\title{
Mortality after neonatal cardiac surgery: Prediction from mean arterial pressure after rewarming in the operating room
}

Ari R. Joffe, MD, ${ }^{a}$ Charlene M.T. Robertson, MD, ${ }^{\text {a,b }}$ Alberto Nettel-Aguirre, PhD, ${ }^{\text {c,e }}$ Ivan M. Rebeyka, MD, a,d Reginald S. Sauve, MD, ${ }^{c, f}$ and The Western Canadian Complex Pediatric Therapies Project Follow-up Group*

From the Departments of Pediatrics ${ }^{\mathrm{a}}$ and Surgery, ${ }^{\mathrm{d}}$ University of Alberta, Edmonton, Alberta; Neonatal and Infant Follow-up Clinic, ${ }^{\mathrm{b}}$ Glenrose Rehabilitation Hospital, Edmonton, Alberta; Departments of Pediatrics $^{c}$ and Community Health Sciences ${ }^{\mathrm{f}}$, University of Calgary, Calgary, Alberta; Biostatistician, Research Methods Team, Faculty of Medicine, University of Calgary, Calgary, Alberta, Canada.

Support was initially provided by the Glenrose Rehabilitation Hospital research trust fund, with ongoing funding from the Registry and Follow-up of Complex Pediatric Therapies Project, Alberta Health and Wellness.

Received for publication Oct 20, 2006; revisions received Jan 19, 2007; accepted for publication Feb 1, 2007.

Address for reprints: Ari R. Joffe, MD, FRCP $(C)$, Department of Pediatrics, 3A3.07 Walter C Mackenzie Center, 8440 112 Street, Edmonton, Alberta, Canada, T6G 2B7 (E-mail: ajoffe@cha.ab.ca).

*D. Moddemann, Winnipeg, Manitoba, Canada; P. Blakley, Saskatoon, Saskatchewan, Canada; A. Ninan, Regina, Saskatchewan, Canada.

J Thorac Cardiovasc Surg 2007;134:311-8

$0022-5223 / \$ 32.00$

Copyright () 2007 by The American Association for Thoracic Surgery

doi:10.1016/j.jtcvs.2007.02.001
Objective: To examine the predictive contribution of mean arterial pressure after rewarming to $\geq 34^{\circ} \mathrm{C}$ in the operating room to mortality after cardiac surgery in infants $\leq 6$ weeks old.

Methods: In this prospective inception cohort study, 70 consecutive infants who had open cardiac surgery with deep hypothermic circulatory arrest when $\leq 6$ weeks old in the years 1996 to 1999 had follow-up to 5 years of age. Demographic, preoperative, operative, and postoperative variables were recorded prospectively. The previously unexplored variables of lowest mean arterial pressure in the operating room after rewarming to $34^{\circ} \mathrm{C}$ were recorded retrospectively from anesthesia records. Predictor variables for death were examined using univariate and multivariate analyses.

Results: Deep hypothermic circulatory arrest time, re-cardiopulmonary bypass in the operating room, duration of mean arterial pressure below 40, 35, 30, and $25 \mathrm{~mm}$ $\mathrm{Hg}$ after rewarming in the operating room, time for lactate to return to $\leq 2 \mathrm{mmol} / \mathrm{L}$ postoperatively, and cardiopulmonary resuscitation were significantly associated with death at 1 and 5 years of age on univariate analysis. Multivariate stepwise forward logistic regression analysis found the duration of mean arterial pressure after rewarming below $30 \mathrm{~mm} \mathrm{Hg}$ (odds ratio 1.094; 95\% confidence interval 1.033-1.158) and cardiopulmonary resuscitation (odds ratio 13.800 , 95\% CI 3.06262.194) were significant predictors of death by 5 years of age. Stepwise multiple regression using pre- and intraoperative variables accounted for $30.1 \%$ of the variability related to mean arterial pressure $\leq 30 \mathrm{~mm} \mathrm{Hg}$ after rewarming.

Conclusion: In these infants, low mean arterial pressure after rewarming in the operating room, even for brief times, is significantly associated with death.

$\mathrm{T}$ There is a growing literature describing the outcomes of infants receiving open cardiac surgery in early infancy. ${ }^{1-3}$ Mortality has been reduced but still remains significant, particularly in patients with some complex lesions such as hypoplastic left heart syndrome. ${ }^{1}$ Several studies have been published regarding predictors of outcomes after congenital heart disease surgery. ${ }^{4-7}$ Most studies find the cause of adverse outcome to be multifactorial, including preoperative, intraoperative, and postoperative conditions and events. ${ }^{1-8}$

Many variables that have been found to predict outcome after surgery for congenital heart disease are not modifiable. Examples include type of lesion, preoperative neurologic examination, preoperative microcephaly, chromosomal anomalies, and socioeconomic status. ${ }^{1-7}$ Also, many postoperative variables such as severity of illness and duration of intensive care may not be modifiable and may be heavily influenced by events and conditions present prior to and during surgery. The mean arterial pressure (MAP) in the operating room (OR) after rewarming to a 


\author{
Abbreviations and Acronyms \\ $\mathrm{CPB}=$ cardiopulmonary bypass \\ DHCA $=$ deep hypothermic circulatory arrest \\ HLHS = hypoplastic left heart syndrome \\ MAP $=$ mean arterial pressure \\ $\mathrm{OR}=$ operating room \\ PRISM $=$ pediatric risk of mortality
}

temperature of $\geq 34^{\circ} \mathrm{C}$, while on or off of cardiopulmonary bypass (CPB), is a potentially modifiable variable. The MAP is a surrogate for the perfusion pressure supplying blood flow to the tissues ${ }^{9,10}$ and may be particularly relevant on rewarming when metabolism is "reactivated." 8

The objective of this study was to examine the predictive contribution to mortality of the potentially modifiable variable of MAP after rewarming in the OR after open cardiac surgery in infants 6 weeks old or less.

\section{Materials and Methods \\ Design}

This prospective descriptive study is part of a larger interprovincial inception cohort study established to examine outcomes of infants $\leq 6$ weeks of age who receive complex, open cardiac surgery. Ethics Boards approvals were obtained prior to onset of the study, and all patients' parents/guardians signed informed consent forms.

\section{Subjects}

The subjects all had complex intracardiac surgery done at $\leq 6$ weeks of age using CPB and deep hypothermic circulatory arrest (DHCA) at the Stollery Children's Hospital, Edmonton, Alberta, through the Western Canadian Children's Heart Network. No child was excluded for any reason.

\section{Procedure}

All infants were enrolled by a nurse research assistant. Clinical and laboratory parameters that had been agreed upon prior to data collection were recorded prospectively; these are described elsewhere $^{11}$ and listed in the results (see Table 2). A new intraoperative variable, the MAP after rewarming to a core temperature of at least $34^{\circ} \mathrm{C}$ in the $\mathrm{OR}$ (on or off of $\mathrm{CPB}$ and before transfer to pediatric intensive care) was obtained by one of the authors (A.J.) by retrospective review of the anesthesia record for each patient and blinded to outcome. Blood pressure was monitored continuously via arterial line in the operating room and recorded by hand by the anesthetist at 5-minute intervals onto the anesthesia record. This variable was recorded as the duration of MAP below specific thresholds $(40,35,30,25$, and $20 \mathrm{~mm} \mathrm{Hg})$ in the operating room after rewarming. Follow-up assessments were scheduled at the Neonatal Follow-up Clinics at the tertiary site of origin in the various provinces. All patients had follow-up data for the primary outcome of mortality during hospitalization, at 1 year, and at 5 years of age.

During the time of this study, there was no protocol for anesthetic management or blood pressure management in the operating
TABLE 1. Primary cardiac diagnoses and surgery for the cohort of 70 infants $\leq 6$ weeks of age

\begin{tabular}{lc}
\hline Cardiac diagnosis (surgical procedure) & Number \\
\hline Hypoplastic left heart syndrome (Norwood procedure) & 26 \\
Transposition of the great arteries \pm ventricular & 14 \\
$\quad$ septal defect (arterial switch procedure) & \\
$\begin{array}{l}\text { Simple total anomalous pulmonary venous connection } \\
\quad \text { (repair) }\end{array}$ & 6 \\
Miscellaneous lesions (repair) & 24 \\
$\quad \begin{array}{l}\text { Truncus arteriosus } \\
\text { Hypoplastic aortic arch (2 with single-ventricle }\end{array}$ & 6 \\
$\quad$ anatomy) & 7 \\
Interrupted aortic arch (1 with single-ventricle & 5 \\
$\quad$ anatomy) & \\
Complex anomalies involving the great arteries or & 6 \\
$\quad$ mitral valve (2 with single-ventricle anatomy) & \\
\hline
\end{tabular}

room. These were left to the discretion of the anesthetist. This "natural variability" in management was important for the observational design of this study. In general, maintenance anesthesia during CPB was with high-dose opioid using fentanyl or sufentanil and supplemented by volatile anesthetic including sevoflurane, desflurane, or isoflurane at the anesthetist's discretion. When inotropes were deemed necessary, dopamine was started, and if not sufficient at a dose of $10 \mu \mathrm{g} \cdot \mathrm{kg}^{-1} \cdot \mathrm{min}^{-1}$, an epinephrine infusion was added. Phenoxybenzamine was not used in these patients, and amrinone or milrinone usage was rare in the operating room.

\section{Statistics}

All data were transferred for entry to The Registry and Follow-up of Complex Pediatric Therapies Project at the Glenrose Rehabilitation Hospital, Edmonton, Alberta. Univariate analyses for death were done using $t$ tests for equality of means preceded by Levene's test for equality of variances, $\chi^{2}$ test with Yates correction or Fisher exact test $(2$ sided $)$ when appropriate. Pearson product moment correlations among variables were done with 2-tailed significance. Bonferroni correction for multiple tests was applied in all cases. Multivariate stepwise forward logistic regression was used to develop prognostic indicators of death from the preoperative, intraoperative, and postoperative periods using the Wald statistic, at a significance level of .05. Stepwise multiple regression using preoperative and operative variables was used to predict the MAP after rewarming variables. SPSS (SPSS, Chicago, Ill), version 12.0 for Windows was used for analysis. The funding agency had no role in data collection, analysis, interpretation, or manuscript approval.

\section{Results}

Seventy consecutive subjects from September 1996 through August 1999 were identified at the time of open cardiac surgery. The primary cardiac diagnoses and surgery are shown in Table 1. Survival outcome is available for all patients. There were 51 survivors (73\%): 13 deaths occurred during the initial hospitalization (19\%), 2 more by 1 year of 
TABLE 2. Demographic, preoperative, operative, and postoperative characteristics of the 70 infants of $\leq 6$ weeks of age with complex intracardiac surgery in relation to death at or before 5 years of age

\begin{tabular}{|c|c|c|c|c|c|}
\hline Demographics/preoperative/operative variables & Total $(\mathbf{n}=70)$ & Survival $(n=51)$ & Death $(n=19)$ & $\chi^{2}, t$, exact tests* & $P$ \\
\hline Gender (male) & $43(61 \%)$ & $32(63 \%)$ & $11(58 \%)$ & .137 & .711 \\
\hline Birth gestation (wk) & $39(2)$ & $39(2)$ & $39(1)$ & .783 & .437 \\
\hline Birth weight $(\mathrm{kg})$ & $3.3(.6)$ & $3.3(.6)$ & $3.2(.5)$ & .648 & .519 \\
\hline Birth head circumference (cm) & $34(2)$ & $34(1)$ & $34(2)$ & .525 & .605 \\
\hline Apgar (5 min) & $8(1)$ & $8(1)$ & $8(.5)$ & - & .999 \\
\hline Chromosomal abnormality & $9(13 \%)$ & $7(14 \%)$ & $2(11 \%)$ & .126 & .722 \\
\hline Age at surgery (d) & $12.5(20)$ & $13(23)$ & $12(11)$ & .155 & .877 \\
\hline Single ventricle anatomy & $30(43 \%)$ & $17(33 \%)$ & $13(68 \%)$ & 6.959 & .008 \\
\hline HLHS & $26(37 \%)$ & $15(29 \%)$ & $11(60 \%)$ & - & .05 \\
\hline TGA & $14(20 \%)$ & $14(28 \%)$ & $0(0 \%)$ & - & .008 \\
\hline STAPVC & $6(9 \%)$ & $6(12 \%)$ & $0(0 \%)$ & - & .180 \\
\hline MISC & $24(34 \%)$ & $16(31 \%)$ & $8(42 \%)$ & - & .412 \\
\hline Cardiopulmonary bypass time (min) & $105(54)$ & $92(36)$ & $140(77)$ & -2.585 & .017 \\
\hline Lowest MAP for $\geq 10$ min on CPB & $20(14)$ & $22(16)$ & $17(7)$ & 1.187 & .239 \\
\hline $\begin{array}{l}\text { Lowest flow for } \geq 10 \text { minute during CPB (mL. } \\
\left.\qquad \mathrm{kg}^{-1} \cdot \min ^{-1}\right)\end{array}$ & $100(24)$ & $99(27)$ & $101(18)$ & -.300 & .765 \\
\hline Lowest temperature $\left({ }^{\circ} \mathrm{C}\right)$ for $\geq 10$ min during $\mathrm{CPB}$ & $24.0(3.2)$ & $23.0(3.4)$ & $24.1(2.9)$ & -.282 & .779 \\
\hline Blood temperature immediately prior to DHCA & $20.5(2.2)$ & $20.6(3.3)$ & $20.1(3.1)$ & 609 & .545 \\
\hline Crossclamp time (min) & $56(21)$ & $52(20)$ & $68(21)$ & -2.953 & .004 \\
\hline DHCA time (min) & $41(22)$ & $36(21)$ & $54(18)$ & -3.479 & .001 \\
\hline $\mathrm{Re}-\mathrm{CPB}$ in $\mathrm{OR}$ & $19(27 \%)$ & $8(16 \%)$ & $11(58 \%)$ & 12.471 & $<.001$ \\
\hline Day 1 postoperative variables & $\mathrm{n}=68$ & $\mathrm{n}=51$ & $\mathrm{n}=17$ & $t$ or $\chi^{2}$ & \\
\hline Highest dopamine on day 1 & $10(5)$ & $10(1)$ & $11(2)$ & -.657 & .519 \\
\hline Highest plasma lactate, day 1 & $8(6)$ & $7(4)$ & $12(18)$ & -2.814 & .011 \\
\hline Time for plasma lactate to return to $\leq 2$ & $16(10)$ & $14(10)$ & $23(10)$ & -.3693 & $<.001$ \\
\hline Time for plasma lactate to return to $\leq 5$ & $5(7)$ & $4(5)$ & $10(10)$ & -2.652 & .016 \\
\hline Lowest arterial pH & $7.33(.09)$ & $7.35(.08)$ & $7.27(.12)$ & 3.035 & .003 \\
\hline Lowest base deficit & $.18(7)$ & $.55(4)$ & $-.91(13)$ & .441 & .665 \\
\hline Day 2-5 postoperative variables & $\mathrm{n}=66$ & $\mathrm{n}=51$ & $\mathrm{n}=15$ & $t$ or $\chi^{2}$ & \\
\hline Highest dopamine & $10(6)$ & $8(4)$ & $14(8)$ & -2532 & .022 \\
\hline Highest plasma lactate & $5(6)$ & $3(3)$ & $10(9)$ & -2.977 & .010 \\
\hline \multicolumn{6}{|l|}{ Variables from any time period } \\
\hline Seizures & $9(13 \%)$ & $6(12 \%)$ & $3(6 \%)$ & - & .696 \\
\hline Cardiopulmonary resuscitation given & $16(23 \%)$ & $5(10 \%)$ & $11(58 \%)$ & - & $<.001$ \\
\hline Extracorporeal membrane oxygenation & $4(6 \%)$ & $0(0 \%)$ & $4(21 \%)$ & - & .004 \\
\hline Days of ventilation & $14(15)$ & $12(12)$ & $19(21)$ & -1.405 & .174 \\
\hline Days of hospitalization & $31(26)$ & $31(25)$ & $32(27)$ & -.179 & .859 \\
\hline $\begin{array}{l}\text { Lowest hemoglobin in the first } 5 \mathrm{~d} \\
\text { postoperatively }\end{array}$ & $111(16)$ & $110(15)$ & $112(20)$ & -.336 & .738 \\
\hline
\end{tabular}

Data given as mean (SD) or $\mathrm{n}(\%)$.

$* t$ test for equality of means preceded by Levene's test for equality of variances; $\chi^{2}$ with Yates correction, or Fisher exact test (2-sided) when appropriate. After Bonferonni correction for multiple analyses, $P$ values of $<.002$ remain significant. CPB, Cardiopulmonary bypass; DHCA, deep hypothermic circulatory arrest; HLHS, hypoplastic left heart syndrome; MAP, mean arterial pressure, $\mathrm{mm} \mathrm{Hg} ;$ MISC, miscellaneous cardiac lesions; STAPVC, simple total anomalous pulmonary venous connection; TGA, transposition of the great arteries.

age $(21 \%)$, and 4 more by 5 years of age (27\%). More details of the findings in this cohort of patients have been published. $^{11}$

\section{Univariate Analyses}

Potential predictors of death at age 5 years available for all 70 subjects and considered in the univariate analysis are shown in Table 2. The variables concerning MAP after rewarming to $34^{\circ} \mathrm{C}$ in the operating room and their relation to mortality during hospitalization and at 1 and 5 years of age are shown in Table 3.

\section{Multivariate Analyses}

All variables that predicted death in the univariate analyses with a $P<.002$ (DHCA time, re-CPB in the OR, MAP after rewarming in the $\mathrm{OR}$, time for plasma lactate to return to 
TABLE 3. Duration of mean arterial pressure below the thresholds after rewarming to at least $34^{\circ} \mathrm{C}$ in the operating room in relation to death at 1 and 5 years of age for 70 infants after complex intracardiac surgery done at $\leq 6$ weeks of age

\begin{tabular}{|c|c|c|c|c|c|}
\hline \multirow[b]{2}{*}{ Outcome period } & \multicolumn{3}{|c|}{ Outcome at initial hospitalization } & \multirow[b]{2}{*}{$T^{*}$} & \multirow[b]{2}{*}{$\boldsymbol{P}$} \\
\hline & Total* & Survival & Death & & \\
\hline Outcome at initial hospitalization & $\mathrm{n}=70$ & $\mathrm{n}=57$ & $\mathrm{n}=12$ & & \\
\hline \multicolumn{6}{|l|}{ Duration (min) of MAP below a threshold of: } \\
\hline $40 \mathrm{~mm} \mathrm{Hg}$ & $19(12)$ & $17(12)$ & $25(10)$ & -2.428 & .024 \\
\hline $35 \mathrm{~mm} \mathrm{Hg}$ & $14(13)$ & $11(12)$ & $23(11)$ & -3.185 & .002 \\
\hline $30 \mathrm{~mm} \mathrm{Hg}$ & $10(12)$ & $8(11)$ & $19(12)$ & -3.318 & .001 \\
\hline $25 \mathrm{~mm} \mathrm{Hg}$ & $5(10)$ & $3(8)$ & $13(14)$ & -2.744 & .016 \\
\hline $20 \mathrm{~mm} \mathrm{Hg}$ & $3(7)$ & $2(6)$ & $6(9)$ & -1.543 & .144 \\
\hline Outcome at 1 year of age & $\mathrm{n}=70$ & $\mathrm{n}=55$ & $\mathrm{n}=15$ & & \\
\hline \multicolumn{6}{|l|}{ Duration (min) of MAP below a threshold of: } \\
\hline $40 \mathrm{~mm} \mathrm{Hg}$ & $19(12)$ & $17(12)$ & $26(9)$ & -3.039 & .005 \\
\hline $35 \mathrm{~mm} \mathrm{Hg}$ & $14(13)$ & $11(12)$ & $24(10)$ & -4.237 & $<.001$ \\
\hline $30 \mathrm{~mm} \mathrm{Hg}$ & $10(12)$ & $7(11)$ & $21(12)$ & -4.123 & .001 \\
\hline $25 \mathrm{~mm} \mathrm{Hg}$ & $5(10)$ & $2(6)$ & $16(14)$ & -3.796 & .002 \\
\hline $20 \mathrm{~mm} \mathrm{Hg}$ & $3(7)$ & $1(5)$ & $7(11)$ & -2.037 & .059 \\
\hline Outcome at 5 years of age & $\mathrm{n}=70$ & $\mathrm{n}=51$ & $\mathrm{n}=19$ & & \\
\hline \multicolumn{6}{|l|}{ Duration (min) of MAP below a threshold of: } \\
\hline $40 \mathrm{~mm} \mathrm{Hg}$ & $19(12)$ & $16(12)$ & $25(8)$ & -3.422 & .001 \\
\hline $35 \mathrm{~mm} \mathrm{Hg}$ & $14(13)$ & $11(12)$ & $22(11)$ & -3.465 & .001 \\
\hline $30 \mathrm{~mm} \mathrm{Hg}$ & $10(12)$ & $6(11)$ & $19(12)$ & -4.149 & $<.001$ \\
\hline $25 \mathrm{~mm} \mathrm{Hg}$ & $5(10)$ & $2(6)$ & $12(14)$ & -3.149 & .005 \\
\hline $20 \mathrm{~mm} \mathrm{Hg}$ & $3(7)$ & $2(5)$ & $6(14)$ & -1.741 & .096 \\
\hline
\end{tabular}

*Data given as minutes (SD). $t$ test for equality of means preceded by Levene's test for equality of variances. After Bonferonni correction for multiple analyses, $P$ values of $\leq .005$ remain significant. MAP, Mean arterial pressure after rewarming to $\geq 34^{\circ} \mathrm{C}$ in the operating room.

$\leq 2 \mathrm{mmol} / \mathrm{L}$ postoperatively, and CPR) or that were considered potentially clinically important (single-ventricle anatomy, hypoplastic left heart syndrome [HLHS], transposition of the great arteries, aortic crossclamp time, lowest arterial $\mathrm{pH}$ day 1 postoperatively, and use of extracorporeal membrane oxygenation) were entered in a stepwise forward logistic regression. The results for predicting death at initial hospital discharge, 1 year of age, and 5 years of age are shown in Table 4. The MAP after rewarming in the OR was the only potentially modifiable variable to be associated with mortality.

\section{MAP on Rewarming}

The significant correlations of the MAP after rewarming in the OR with selected pre- and intraoperative variables is shown in Table 5. No significant correlation of the

TABLE 4. Multivariate stepwise forward logistic regression of significant predictor variables* for death in 70 infants of $\leq 6$ weeks of age with complex intracardiac surgery

\begin{tabular}{|c|c|c|c|c|c|c|c|}
\hline Model & Variables & B & SE & Wald & Sign & Odds ratio & $95 \% \mathrm{Cl}$ \\
\hline \multirow[t]{3}{*}{ A. Death by hospital discharge } & Duration of $\mathrm{MAP} \leq 30 \mathrm{~mm}$ & & & & & & \\
\hline & $\mathrm{Hg}(\min )$ & .106 & .046 & 5.342 & .021 & 1.112 & $1.016-1.216$ \\
\hline & CPR & 4.508 & 1.162 & 15.036 & $<0.001$ & 90.700 & $9.292-885.311$ \\
\hline \multirow[t]{3}{*}{ B. Death by 1 year of age } & Duration of $\mathrm{MAP} \leq 25 \mathrm{~mm}$ & & & & & & \\
\hline & $\mathrm{Hg}(\min )$ & .144 & .045 & 10.254 & .001 & 1.155 & $1.058-1.262$ \\
\hline & CPR & 3.844 & 1.066 & 13.009 & .000 & 46.720 & $5.785-377.313$ \\
\hline \multirow[t]{3}{*}{ C. Death by 5 years of age } & Duration of $\mathrm{MAP} \leq 30 \mathrm{~mm}$ & & & & & & \\
\hline & $\mathrm{Hg}(\min )$ & .090 & .029 & 9.418 & .002 & 1.094 & $1.033-1.158$ \\
\hline & CPR & 2.625 & .768 & 11.674 & .001 & 13.800 & $3.062-62.194$ \\
\hline
\end{tabular}

*The variables entered included: single-ventricle anatomy, hypoplastic left heart syndrome, transposition of the great arteries, aortic crossclamp time, deep hypothermic circulatory arrest time, re-cardiopulmonary bypass in the operating room, time for plasma lactate to return to $\leq 2 \mathrm{mmol} / \mathrm{L}$ on the day postoperative, lowest arterial $\mathrm{pH}$ on the day postoperative, CPR given at any time, extracorporeal membrane oxygenation, and duration (minutes) of MAP after rewarming to $34^{\circ} \mathrm{C}$ in the operating room below thresholds of $40,35,30$, and $25 \mathrm{~mm} \mathrm{Hg}$. CPR, cardiopulmonary resuscitation; $M A P$, mean arterial pressure. 
TABLE 5. Significant correlations with duration of mean arterial pressure after rewarming in the operating room for 70 infants after complex intracardiac surgery done at $\leq 6$ weeks of age

\begin{tabular}{llc}
\hline Variable & $\begin{array}{c}\text { Duration MAP } \leq \mathbf{3 0} \\
\mathbf{m m ~ H g}\end{array}$ & $\begin{array}{c}\text { Duration MAP } \leq \mathbf{2 5} \\
\mathbf{m m ~ H g}\end{array}$ \\
\hline HLHS & $\mathrm{r}=.271, P=.024$ & $r=.206, P=.088$ \\
TGA & $r=-.201, P=.096$ & $\mathrm{NS}$ \\
CPB time & $r=.482, P<.001$ & $r=.578, P<.001$ \\
Crossclamp time & $r=.206, P=.087$ & $r=.272, P=.023$ \\
DHCA time & $r=.335, P=.003$ & $r=.407, P<.001$ \\
Repeat CPB in & $r=.529, P<.001$ & $r=.550, P<.001$ \\
\multicolumn{1}{c}{ operating room } & & \\
\hline
\end{tabular}

Variables with $P>.10$ include: birth weight, gestational age, singleventricle anatomy, highest dopamine dose preoperatively, highest lactate preoperatively, days of ventilation preoperatively, and lowest flow on CPB. After Bonferonni correction for multiple analyses, $P$ values of $\leq .004$ remain significant. There were $\mathrm{n}=70$ for preoperative variables, $\mathrm{n}=68$ for day 1 variables, and $n=66$ for day $2-5$ variables. $C P B$, Cardiopulmonary bypass; $D H C A$, deep hypothermic circulatory arrest; $H L H S$, hypoplastic left heart syndrome; $M A P$, mean arterial pressure after rewarming to $34^{\circ} \mathrm{C}$ in the operating room; TGA, transposition of the great arteries.

MAP after rewarming in the OR was found with birth weight, gestational age, single-ventricle anatomy, highest dopamine dose preoperatively, highest plasma lactate preoperatively, days of ventilation preoperatively, or lowest flow on CPB. The variables from preoperative and operative periods that had a correlation with a $P \leq .1$ (Table 5) were entered into a stepwise multiple regression to predict the MAP after rewarming in the OR. The multiple regression accounted for $30.1 \%$ of the variability for MAP $\leq 30 \mathrm{~mm} \mathrm{Hg}$ and $38.4 \%$ of the variability for MAP $\leq 25 \mathrm{~mm} \mathrm{Hg}$ (Table 6). Finally, duration of MAP $\leq 30 \mathrm{~mm} \mathrm{Hg}$ and $\leq 25 \mathrm{~mm} \mathrm{Hg}$ after rewarming in the OR showed no correlation with the time for plasma lactate to return to $\leq 5 \mathrm{mmol} / \mathrm{L}$ day 1 postoperatively, time for plasma lactate to return to $\leq 2 \mathrm{mmol} / \mathrm{L}$ day 1 postoperatively, highest dopamine dose day 1 postoperatively, highest epinephrine dose day 1 postoperatively, or high- est plasma lactate day 2 postoperatively. There was a significant correlation with the highest plasma lactate on postoperative day 1: for duration of MAP $\leq 35 \mathrm{~mm} \mathrm{Hg}$ $(r=.366, P=.002)$ and for duration of MAP $\leq 25 \mathrm{~mm}$ $\mathrm{Hg}(r=.316, P=.009)$.

The lowest values of MAP after rewarming in the OR were examined more closely to determine their timing in relation to $\mathrm{CPB}$. The lowest values occurred while on $\mathrm{CPB}$ in 35\%, while off CPB in 54\%, and overlapping both times in $12 \%$. The period on $\mathrm{CPB}$ after rewarming to $34^{\circ} \mathrm{C}$ accounted for $73 \%$ and $93 \%$ of the MAP values less than 30 $\mathrm{mm} \mathrm{Hg}$ and $25 \mathrm{~mm} \mathrm{Hg}$, respectively.

\section{Discussion}

In this observational study, many variables were examined to determine their relation to mortality after complex open cardiac surgery in infants $\leq 6$ weeks old. The study took advantage of the variability in clinical management of MAP in the OR to examine the predictive potential of this variable. The main finding of this study is that a low MAP after rewarming in the OR is a significant predictor of death at 5 years of age in both univariate and multivariate stepwise forward logistic regression analyses. Furthermore, only $30 \%$ to $38 \%$ of the variance related to MAP on rewarming in the OR could be accounted for in stepwise multiple regressions. To our knowledge, MAP after rewarming in the OR has not been previously examined in predicting outcomes after congenital heart disease surgery. Our data suggest that a MAP after rewarming in the OR of $\geq 35 \mathrm{~mm} \mathrm{Hg}$ is desirable and that a MAP below this may be detrimental, even for brief periods of time.

There are theoretical reasons to suggest that a low MAP immediately after rewarming may be a direct cause of poor outcome. The goal in treatment of shock is to maintain perfusion pressure above the critical point below which blood flow cannot be effectively maintained in individual organs. ${ }^{9,10}$ Below a certain threshold there will be inadequate organ and tissue perfusion, and cellular

TABLE 6. Stepwise multiple regressions to predict mean arterial pressure after rewarming to $34^{\circ} \mathrm{C}$ in the operating room of 70 infants after complex intracardiac surgery done at $\leq 6$ weeks of age

\begin{tabular}{|c|c|c|c|c|c|c|}
\hline Model & Variable & Adj $r^{2}$ & Slope & Standard error & $T$ & $P$ \\
\hline \multirow{4}{*}{$\begin{array}{l}\text { A. Duration of MAP } \leq 30 \mathrm{~mm} \mathrm{Hg} \\
\text { after rewarming (min) }\end{array}$} & Need for re- & & & & & \\
\hline & $\mathrm{CPB}$ in $\mathrm{OR}$ & .269 & 7.302 & 3.630 & 2.012 & .048 \\
\hline & CPB time & .301 & .074 & .029 & 2.582 & .012 \\
\hline & HLHS & .334 & 5.560 & 2.663 & 2.088 & .041 \\
\hline \multirow{2}{*}{$\begin{array}{l}\text { B. Duration of MAP } \leq 25 \mathrm{~mm} \mathrm{Hg} \\
\text { after rewarming (min) }\end{array}$} & CPB time & .324 & .093 & .018 & 5.148 & $<.001$ \\
\hline & DHCA time & .384 & .123 & .045 & .271 & .007 \\
\hline
\end{tabular}

Variables used included HLHS, TGA, CPB time, crossclamp time, DHCA time, and need for re-CPB in operating room. CPB, Cardiopulmonary bypass; DHCA, deep hypothermic circulatory arrest; $H L H S$, hypoplastic left heart syndrome; $M A P$, mean arterial pressure on rewarming to $34^{\circ} \mathrm{C}$ in the operating room; $O R$, operating room; $T G A$, transposition of the great arteries. 
injury. This threshold may be especially important after cardiac surgery in infants in view of their significant systemic inflammatory response to $\mathrm{CPB},{ }^{12,13}$ making the microcirculation particularly vulnerable to an inadequate perfusion pressure. ${ }^{14}$ There is altered regulation of microvascular tone, ${ }^{8,14}$ plugging of the microcirculation due to microthrombi and cellular adhesion events, ${ }^{8,14}$ and a heterogeneous alteration of capillary density and perfusion. ${ }^{15}$ In this study, the period of low MAP after rewarming included time on CPB when it can be argued that there is normal systemic blood flow, regardless of the patient MAP. The period on CPB after rewarming to $34^{\circ} \mathrm{C}$ accounted for $73 \%$ and $93 \%$ of the MAP values less than $30 \mathrm{~mm} \mathrm{Hg}$ and $25 \mathrm{~mm} \mathrm{Hg}$, respectively. This suggests that it is not simply systemic blood flow that is important; rather, it may be perfusion pressure to the microcirculation of the tissues that is critical.

There is clinical evidence to support this theoretical argument for a direct adverse effect on survival of a low MAP. In the pediatric risk of mortality (PRISM) score, the low systolic blood pressure limits for predicting stepwise increased mortality rates in infants were $<55 \mathrm{~mm}$ $\mathrm{Hg}$ and $<40 \mathrm{~mm} \mathrm{Hg}{ }^{16}$ This was also the case for neonates in the more recent PRISM III score. ${ }^{17}$ In the pediatric logistic organ dysfunction score, the low systolic blood pressure limits to assign stepwise increased cardiovascular organ dysfunction in term neonates are $<65 \mathrm{~mm} \mathrm{Hg}$ and $<35 \mathrm{~mm} \mathrm{Hg} .{ }^{18}$ Recent consensus guidelines on management of sepsis in adults suggest that a MAP $\geq 60 \mathrm{~mm} \mathrm{Hg}$ is needed to achieve adequate tissue blood flow. ${ }^{10}$ Similar consensus guidelines in pediatrics have recommended that the perfusion pressure (MAP minus central venous pressure) be kept $\geq 55 \mathrm{~mm} \mathrm{Hg}$ in term newborns to maintain organ blood flow. ${ }^{9}$ Early phases of inflammatory processes may be a particularly vulnerable time. When supraphysiologic goals of resuscitation are used in established critical illness, there is no effect on outcome ${ }^{19}$; however, when they are used early in severe sepsis ${ }^{20}$ or high-risk surgical patients, ${ }^{21}$ there is significant improvement in mortality and organ dysfunction. Comprehensive early therapy may limit the progression of the cascades leading to multiple organ dysfunction and death. ${ }^{19}$

The current study supports the theory that a low MAP may lead to tissue hypoxia, an exaggerated inflammatory response, multiple organ dysfunction, and death. The MAP variables on rewarming were significantly predictive of mortality in stepwise forward logistic regressions that included factors from all time periods of hospitalization. In addition, using many variables from the preand intraoperative time periods in a stepwise multiple regression could only explain $<40 \%$ of the variability related to MAP after rewarming, suggesting that most of the predictive ability of MAP on rewarming was not due to another interrelated variable. The MAP on rewarming correlated with the lactate on the first postoperative day. This suggests that the MAP was a valid surrogate for tissue perfusion and that a threshold of perfusion had been crossed, resulting in tissue hypoxia and anaerobic metabolism. The lack of correlation to dopamine dose or epinephrine dose or the time for lactate to return to $\leq 5$ $\mathrm{mmol} / \mathrm{L}$ or $\leq 2 \mathrm{mmol} / \mathrm{L}$ on the first postoperative day suggests this was not due to ongoing myocardial dysfunction. It is possible that the low MAP led to the ultimate development of "cytopathic hypoxia," leading to organ dysfunction and death. ${ }^{19,22}$ Indeed, death was associated with multiple organ dysfunction syndrome in $10 / 13(77 \%)$ of the deaths during initial hospitalization, rather than sudden death. It is also plausible that initial "cytopathic hypoxia" may have caused permanent microvascular or cellular injury that resulted in the late deaths up to 5 years of age associated with subsequent illness or surgery. This hypothesis merits further investigation, as we are aware of no data to confirm or refute this possibility.

Some authors have described excellent outcomes after the Norwood procedure using phenoxybenzamine and milrinone in the operating room to lower systemic vascular resistance. ${ }^{23-25}$ In these studies, the MAP in the first 48 hours postoperatively ranged from 44 to $62 \mathrm{~mm}$ $\mathrm{Hg}^{23-25}$ and thus was much higher than that predicting mortality in the current study. In those studies epinephrine and norepinephrine were used to maintain a MAP greater than $45 \mathrm{~mm} \mathrm{Hg}$ on separation from $\mathrm{CPB} .{ }^{23-25}$ The results of these studies suggest that vasodilation is not in itself deleterious as long as MAP is maintained in a reasonable range.

These results apply to a very select patient population, those who had neonatal cardiac surgery requiring DHCA during the period 1996 to 1999, and include a large number of HLHS and other complex lesions. The 30-day postoperative mortality during this period for this complex group of neonates was 10/70 (14.3\%). Whether the results still apply in the current era of neonatal cardiac surgery cannot be proven with these data. From 2001 to 2004, our 30-day mortality for complex neonatal open cardiac surgery was $8 / 170(4.7 \%)$; 30-day mortality for cardiac surgery in those $<17$ years was $24 / 2072(1.2 \%)$.

There are limitations to this study. This was not a randomized trial and therefore the associations shown cannot be definitively identified as cause and effect. The study included a relatively small and heterogeneous group of patients having neonatal cardiac surgery and therefore there may be unaccounted for differences between patients that confound the interpretation of the results. Many of the variables were highly correlated and 
therefore the low MAP may be a manifestation of other underlying etiologic factors, in and of itself not harmful. For example, some specific variables such as anesthetic management and OR inotrope use were not protocolized and not recorded for this study and may confound the interpretation of why low MAP is associated with mortality. The exact cause of the low MAP in this study could not be ascertained. Theoretically, it could be due to low systemic vascular resistance, low cardiac output, or both. That most of the low MAP values occurred while on CPB may suggest that a low MAP was predominately due to low systemic vascular resistance; however, this is not certain because we were unable to record the flow on $\mathrm{CPB}$ after rewarming in the operating room. We were also unable to determine what therapeutic interventions were attempted for a low MAP in the operating room. Given this, we cannot determine the best therapeutic option when faced with a low MAP. Nevertheless, this observational study suggests that a novel parameter, the MAP after rewarming in the operating room, is associated with outcome and warrants further investigation.

In view of these limitations, one could argue that the MAP on rewarming variables are associated with outcome simply because they are a marker for worse cardiac function postoperatively. Whether intervention to increase the MAP will improve outcome or have its own complications can only be answered by further study.

\section{Conclusions}

Despite these limitations, the main finding of the significant association of MAP after rewarming in the OR and death during hospitalization, at 1 year, and at 5 years of age is we believe, biologically plausible and likely causative. We recommend caution in accepting a low MAP in these infants after rewarming in the OR. We suggest that the time after rewarming may be a vulnerable period for the tissue microcirculation, and for this reason, the low MAP on reactivation of metabolism with rewarming may be a causative factor contributing to outcome. This observation is a novel finding, is hypothesis generating, and should lead to further investigation.

We sincerely thank the parents of these very ill infants that have cooperated so positively with our follow-up programs. We thank Drs J. Dyck, J. Harder, and E. Phillipos for their support of this research. We thank the research staff that make this outcome study possible: H. Christianson and D. Anseeuw-Deeks, Calgary, Alberta, Canada; V. Debooy, Winnipeg, Manitoba, Canada; R. Kleisinger, Regina, Saskatchewan, Canada; L. Munro, Saskatoon, Saskatchewan, Canada; and G. Alton and L. Sanders, Edmonton, Alberta, Canada.

\section{References}

1. McElhinney DB, Wernovsky G. Outcomes of neonates with congenital heart disease. Curr Opin Pediatr. 2001;13:104-10.
2. Majnemer A, Limperopoulos C. Developmental progress of children with congenital heart defects requiring open heart surgery. Semin Pediatr Neurol. 1999;6:12-9.

3. Mahle WT, Wernovsky G. Long-term developmental outcome of children with complex congenital heart disease. Clinics in Perinatology. 2001;28:235-47.

4. Limperopoulos C, Majnemer A, Shevell MI, Rohlicek C, Rosenblatt B, Tchervenkov C, et al. Predictors of developmental disabilities after open heart surgery in young children with congenital heart disease. J Pediatr. 2002;141:51-8.

5. Bellinger DC, Wypij D, Kuban KCK, Rappaport LA, Hickey PR, Wernovsky G, et al. Developmental and neurological status of children at 4 years of age after heart surgery with hypothermic circulatory arrest or low-flow cardiopulmonary bypass. Circulation. 1999;100:526-32.

6. Goldberg CS, Schwartz EM, Brunberg JA, Mosca RS, Bove EL, Schork A, et al. Neurodevelopmental outcome of patients after the Fontan operation: a comparison between children with hypoplastic left heart syndrome and other functional single ventricle lesions. J Pediatr. 2000; 137:646-52.

7. Forbess JM, Visconti KJ, Hancock-Friesen C, Howe RC, Bellinger DC, Jonas RA. Neurodevelopmental outcome after congenital heart surgery: results from an institutional registry. Circulation. 2002; 106(Suppl I):I95-102.

8. DuPlessis AJ. Mechanisms of brain injury during infant cardiac surgery. Semin Pediatr Neurol. 1999;6:32-47.

9. Carcillo JA, Fields AI, Task Force Committee Members. Clinical practice parameters for hemodynamic support of pediatric and neonatal patients in septic shock. Crit Care Med. 2002;30: 1365-78.

10. Task Force of the American College of Critical Care Medicine, Society of Critical Care Medicine. Practice parameters for hemodynamic support of sepsis in adult patients in sepsis. Crit Care Med. 1999;27: 639-60.

11. Robertson CMT, Joffe AR, Sauve RS, Rebeyka IM, Phillipos EZ, Dyck JD, et al. Outcomes from an interprovincial program of newborn open heart surgery. J Pediatr. 2004;144:86-92.

12. Mou SS, Haudek SB, Lequier L, Pena O, Leonard S, Nikaidoh H, et al. Myocardial inflammatory activation in children with congenital heart disease. Crit Care Med. 2002;30:827-32.

13. Lequier L, Nikaidoh H, Leonard SR, Bokovoy JL, White ML, Scannon PJ, et al. Preoperative and postoperative endotoxemia in children with congenital heart disease. Chest. 2000;117:1706-1712.

14. Ince C, Sinaasappel M. Microcirculatory oxygenation and shunting in sepsis and shock. Crit Care Med. 1999;27:1369-77.

15. De Backer D, Creteur J, Preiser JC, Dubois MJ, Vincent JL. Microvascular blood flow is altered in patients with sepsis. Am J Respir Crit Care Med. 2002;166:98-104.

16. Pollack MM, Ruttimann UE, Getson PR. Pediatric risk of mortality (PRISM) score. Crit Care Med. 1988;16:1110-6.

17. Pollack MM, Patel KM, Ruttimann UE. PRISM III: an updated pediatric risk of mortality score. Crit Care Med. 1996;24: 743-52.

18. Leteurtre S, Martinot A, Duhamel A, Proulx F, Grandbastien B, Cotting J, et al. Validation of the Pediatric Logistic Organ Dysfunction (PELOD) score: prospective, observational, multicentre study. Lancet. 2003;362:192-7.

19. Joffe AR. Critical care medicine: major changes in dogma of the past decade. J Intensive Care Med. 2001;16:177-92.

20. Rivers E, Nguyen B, Havstad S, Ressler J, Muzzin A, Knoblich B, et al. Early goal-directed therapy in the treatment of severe sepsis and septic shock. N Engl J Med. 2001;345:1368-77.

21. Kern JW, Shoemaker WC. Meta-analysis of hemodynamic optimization in high-risk patients. Crit Care Med. 2002;30:1686-92.

22. Fink MP. Cytopathic hypoxia. Mitochondrial dysfunction as a mechanism contributing to organ dysfunction in sepsis. Crit Care Clin. 2001;17:219-37.

23. Hoffman GM, Tweddell JS, Ghanayem HS, Mussatto KA, Stuth 
EA, Jaquis RDB, et al. Alteration of the critical arteriovenous oxygen saturation relationship by sustained afterload reduction after the Norwood procedure. J Thorac Cardiovasc Surg. 2004;127: 738-45.

24. Hoffman GM, Mussetto KA, Brosig CL, Ghanayem NS, Musa N, Fedderly RT, et al. Systemic venous oxygen saturation after the
Norwood procedure and childhood neurodevelopmental outcome. J Thorac Cardiovasc Surg. 2005;130:1094-100.

25. Ghanayem HS, Jaquiss RDB, Cava JR, Frommelt PC, Mussatto KA, Hoffman GM, et al. Right ventricle-to-pulmonary artery conduit versus Blalock-Taussig shunt: a hemodynamic comparison. Ann Thorac Surg. 2006;82:1603-10.

\section{Interactive eLearning Activities http://learning.ctsnet.org}

The Joint Council on Thoracic Surgery Education was pleased to introduce a series of unique eLearning activities to CTSNet users at the AATS annual meeting in Philadelphia. Sponsored by several cardiothoracic surgical groups, this exciting new educational tool contains narrated videos of actual surgical procedures followed by a series of questions and an evaluation to earn Continuing Medical Education credit.

* Diagnosis and Management of Complications of Mitral Valve Repair

* Off Pump Coronary Artery Bypass

* OPCAB Debriefing

* Pediatric Cardiopulmonary Bypass Emergency Situations

\section{Experience these new educational tools today and provide us with your feedback. Go to: http://learning.ctsnet.org}

William E. Baumgartner, Chair

Joint Council on Thoracic Surgery Education

$$
\text { Sponsored By: }
$$

American Association for Thoracic Surgery

The Society of Thoracic Surgeons

European Association for Cardio-Thoracic Surgery

Children's Memorial Hospital 